\title{
Fossil Fuel Producing Economies Have Greater Potential for Industrial Interfuel Substitution
}

\author{
Jevgenijs Steinbuks* \\ Development Research Group, The World Bank \\ and \\ Badri G. Narayanan \\ Center for Global Trade Analysis, Purdue University
}

October 31, 2014

\begin{abstract}
This study analyzes industrial interfuel substitution in an international context using a large unbalanced panel dataset of 63 countries. We find that compared to other countries fossil fuel producing economies have higher short-term interfuel substitution elasticities. This difference increases further in the long run as fossil fuel producing countries have a considerably longer adjustment of their fuel-using capital stock. These results imply lower economic cost for policies aimed at climate abatement and more efficient utilization of energy resources in energy-intensive economies.

JEL: L71, Q41

Keywords: dynamic linear logit, fossil fuel production, industrial energy demand, international interfuel substitution
\end{abstract}

\section{Introduction}

The degree of substitution among different energy services shapes the industrial energy demand and has serious implications for the ongoing climate change debates across the world. Many economy-wide computable general equilibrium (CGE) models (Burniaux and Truong, 2002; Paltsev et al., 2005; Burniaux and Château, 2008) and large scale partial equilibrium energy and climate models (Manne and Richels, 2005; Bosetti et al., 2006; Kim et al., 2006) depend critically on this aspect. Therefore, various aspects of estimation of interfuel substitution elasticities have been explored in the energy and economic literatures.

Most of the studies on industrial interfuel substitution use time-series data from individual countries, and have limited generalizability for broader energy

${ }^{*}$ Corresponding author. Address: 1818 H Street NW, Washington, DC 20433. Phone: +1 (202) 473-9345. E-mail: jsteinbuks@worldbank.org 
and climate policy debates. ${ }^{1}$ Econometric analysis of industrial interfuel substitution using international cross country data (see Table 1 for a summary of most relevant studies) was until recently restricted to a handful of studies focusing mainly on few developed economies. The only exception is a recent study by Serletis et al. (2010b), which estimated industrial interfuel substitution elasticities for a larger (though still limited) number of countries. In all these studies, the demand for fuels is modeled as a function of input prices and output following standard derivations based on economic theory.

This paper extends the existing literature on industrial interfuel substitution in an international context in two important aspects. First, it estimates econometric model of industrial interfuel substitution using a large unbalanced panel dataset of 63 countries. Based on the model's estimates, it calculates own price and cross price elasticities of fuel demand across this large dataset, thus providing the most generalizable evidence for international interfuel substitution up to date.

Second, it recognizes the significance of non-price factors, focusing specifically on differences between fuel-producing and non-producing economies. These differences can be significant for two reasons explained in the economic literature. First, transaction (e.g., transportation, storage, and import clearance) costs and differences in fuel characteristics (e.g., energy and carbon content) render domestically produced fuels to be imperfect substitutes for foreign commodities (Armington, 1969). If this is the case, the degree of interfuel substitution will be higher in the fossil fuel producing economies. For example, in the presence of low production (i.e., extraction) and high transactions costs, domestically produced coal will be able to compete against imported oil and natural gas, whereas imported coal won't. Several recent studies attempted to estimate Armington elasticities of substitution for different fuels. The size of estimated elasticities was drastically different across these studies, starting from close to zero (Welsch, 2008) to above twenty (Balistreri et al., 2010). These studies use different data and econometric methods, and their results are difficult to reconcile.

Second, many resource-rich countries have historically subsidized the production of their energy resources for the purposes of economic stimulation, enhanced trade performance, inflation control, and energy security (Kosmo, 1987). According to International Energy Agency (IEA) estimates, total subsidies to fossil fuel consumption in 37 non-OECD countries amounted in 2008 to USD 557 billions, almost five times the yearly bilateral aid flows to developing countries in the form of Official Development Assistance (Burniaux and Château, 2011). Figure 1 demonstrates that only in the recent years fuel consumption taxes in oil and natural gas-rich countries converged to (and even exceeded) the levels of countries with no natural resources. ${ }^{2}$ And the taxes on coal consumption are still considerably lower in coal-rich economies. Kosmo (1987) demonstrated that such policies encourage over-investment in energy-intensive

\footnotetext{
${ }^{1}$ For an excellent recent survey of these studies, see Stern (2012).

${ }^{2}$ Figure 1 excludes several oil exporting countries where fossil fuel subsidies are still huge, amounting to $10 \%$ or more of GDP (Burniaux and Château, 2011, annex II)
} 


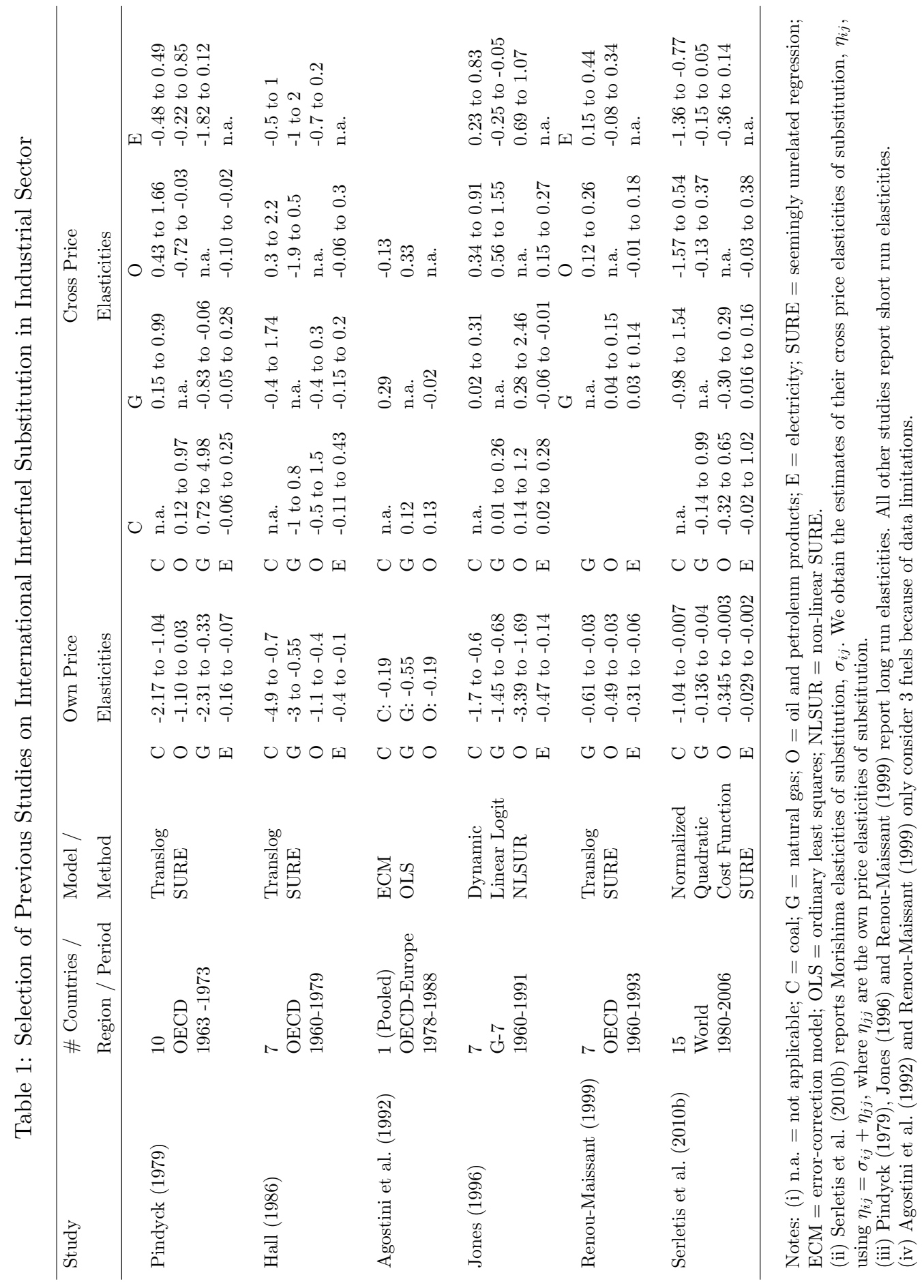




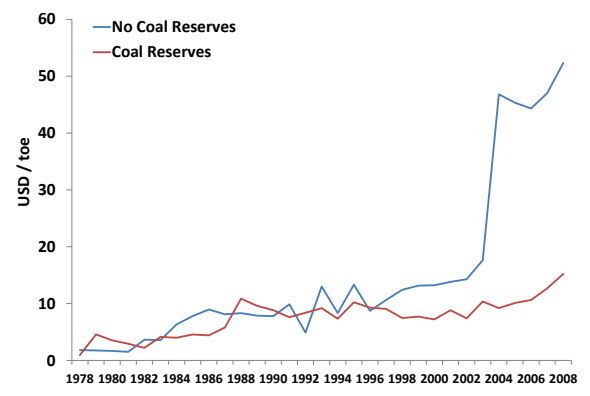

(a) Coal

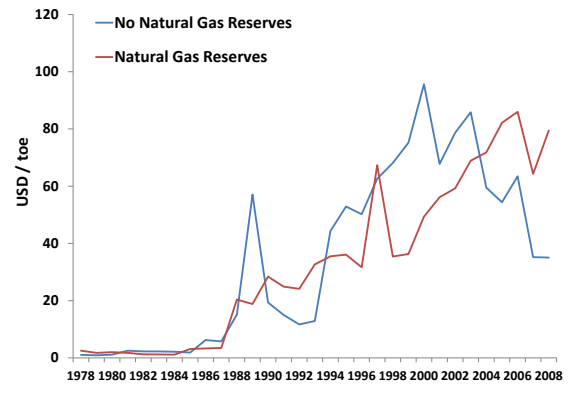

(b) Natural Gas

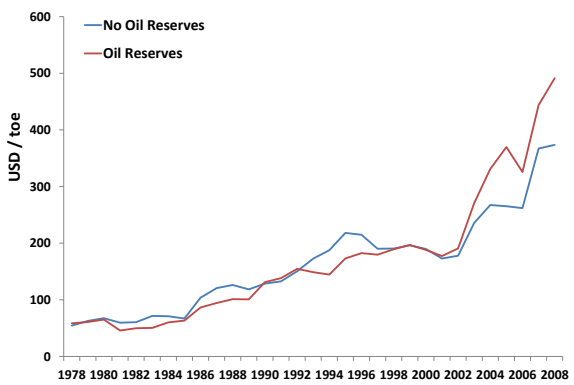

(c) Petroleum Products

Figure 1: Average Industry Real Tax Rates on Fossil Fuels across Countries (Source: IEA Energy Prices and Taxes, EIA International Energy Statistics) 
industries at the expense of other sectors. Heavy capital investment in a particular fuel-using sector will mean difficulties in shifting to another fuel sector in short and medium run because switching to alternative fuels are not always technologically feasible (Steinbuks, 2012) or are too costly to implement (Jacoby and Wing, 1999). Combined with organizational barriers to technology adoption, bounded rationality, and information asymmetries, energy subsidies may result in an energy and carbon "lock-in" (Unruh, 2000), and negatively affect the degree of interfuel substitution.

To evaluate these arguments we calculate own price and cross price elasticities of fuel demand separately across country groups based on their potential to produce fossil fuels. Our econometric results lend support for both arguments. For evidence of carbon lock-in we find that countries with a potential to produce any of the available fossil fuels (i.e., coal, natural gas, and oil) have a considerably longer adjustment of fuel-using capital stocks. For these, more energy-intensive countries, the share of same year response to fuels' price change was less than fifty percent as opposed to ninety percent in countries with no potential to produce fossil fuels. As a result, countries with a potential to produce any of available fossil fuels have considerably higher difference between short and long run elasticities of fuel substitution.

As for evidence of transaction costs argument, we find that, for most fuel pairs, estimated elasticities of fuel substitution are considerably higher for the countries with a potential to produce all fossil fuels or at least one fossil fuel. For example, short run cross price elasticity of coal with respect to electricity prices (the largest in the sample) is more than four times higher for countries with a potential to produce any fossil fuels than for countries with no potential to produce fossil fuels. Moreover, in many cases short run elasticities of fuel substitution for countries with a potential to produce fossil fuels are higher than long run elasticities for countries with no potential to produce fossil fuels.

Our results are important in the light of recent efforts by the international community to reduce carbon emissions (IPCC, 2007) and fossil fuel subsidies (IEA et al., 2010). To demonstrate the quantitative significance of our findings we use calculated elasticities to evaluate the effects of a carbon tax and reduction in oil subsidies using GTAP-E computable general equilibrium modelling framework (Burniaux and Truong, 2002; McDougall and Golub, 2007). Simulation results reported in Steinbuks and Narayanan (2013) demonstrate that, compared to the baseline case of uniform elasticities of fuel substitution, a carbon tax results in a greater decline in coal consumption and a smaller decline in industrial output in fossil fuel producing economies. Similarly, a reduction in oil subsidies would result in a greater decline in production of oil and oil products and a smaller decline in industrial output in fossil fuel producing countries. Greater potential for industrial interfuel substitution in more energy-intensive fossil fuel producing economies thus implies a lower economic cost for policies aimed at climate abatement and more efficient utilization of energy resources. 


\section{Model and Empirical Specification}

The purpose of this section is to present an econometric model for estimating parameters of fuel demand function. Ideally, such a model should explicitly account for the adjustments of capital stocks of energy-using technologies. Dynamic structural econometric models that account for the adjustment of energy-using capital stocks are well established in the economic literature on energy demand (Berndt et al., 1981; Pindyck and Rotemberg, 1983; Popp, 2001; Sue Wing, 2008; Steinbuks and Neuhoff, 2014). However, their implementation in the econometric analysis of interfuel substitution in an international context is not possible due to data limitations on fuel-using capital. This study takes the next available alternative, and, following previous literature, treats capital stocks as dynamic unobserved variables.

The basic assumption underlying the econometric model is that a fuel-using industrial sector in each country is represented by a neo-classical agent (firm) that solves the cost-minimization problem. The firm's production function requires the use of four energy inputs: coal, natural gas, petroleum products, and electricity. It is assumed that the agent's cost is weakly separable in energy and other (e.g. labor and capital) inputs, and the corresponding cost function is a continuous, nondecreasing, concave, and linear homogenous function of input prices. While these assumptions (especially those of separability and homotheticity) are quite restrictive, they allow us to derive conditional input demand functions for energy inputs without explicit consideration of other inputs.

The empirical model adopted in this study is the dynamic version of the linear logit model suggested by Considine and Mount (1984) and extended by Considine (1990), which is widely employed in the empirical literature on interfuel substitution (Considine, 1989; Jones, 1995, 1996; Urga and Walters, 2003; Brännlund and Lundgren, 2004; Steinbuks, 2012). The advantage of this functional form is that it is better suited to satisfy the restrictions of economic theory and is consistent with more realistic adjustment of the unobserved capital stocks to input price changes. Jones (1995) and Urga and Walters (2003) compared the predictions of the dynamic specifications of translog and linear logit models. Both studies concluded that a linear logit specification yields more robust results and should, therefore, be preferred in the empirical analysis of interfuel substitution. ${ }^{3}$

As the model is widely employed in the interfuel substitution literature, in this paper we present only main derivations, final estimating forms, and elasticity formulas. Interested reader may refer to Considine and Mount (1984) and Considine (1990) for more details. A dynamic version of the linear logit model can be expressed in terms of a set of non-homothetic cost shares with non-neutral technical change as follows:

\footnotetext{
${ }^{3}$ Other recent approaches to econometric modelling of interfuel substitution (Serletis and Shahmoradi, 2008; Serletis et al., 2010a,b, 2011) use globally flexible functional forms (Fourier, AIM), as well as locally flexible (NQ, translog) functional forms. Sorting between the results based on these approaches and the one adopted here is beyond the scope of this paper.
} 


$$
\frac{P_{i t}}{C_{t}}\left(\frac{\partial C_{t}}{\partial P_{i t}}\right)=S_{i t}=\frac{\exp \left(f_{i t}\right)}{\sum_{i, j=c, g, o, e} \exp \left(f_{i t}\right)},
$$

in which

$$
f_{i t}=\mu_{i}+\sum_{i, j=c, g, o, e} \phi_{i j} \ln P_{j t}+\gamma^{\prime} W_{t}+\lambda \ln Q_{i, t-1}+\varepsilon_{i t},
$$

and where $C_{t}$ is the total cost in period $t ; P_{j t}$ and $Q_{i t}$ are the prices and quantities for coal, $c$, natural gas, $g$, petroleum products, $o$, and electricity, $e$, respectively; $W=\left[w_{1}, w_{2}, \ldots, w_{m}\right]$ is a vector of control variables; $\mu_{i}, \phi_{i j}$, and $\gamma=\left[\gamma_{i 1}, \gamma_{i 2}, \ldots, \gamma_{i m}\right]$ are unknown parameters, $\lambda$ is a parameter measuring the speed of dynamic adjustment, and $\varepsilon_{i t}$ are assumed to be normally distributed random disturbances.

Considine (1990) argued that the chosen specification has several advantages. First, the predicted shares are guaranteed to be positive and add up to one given the exponential form of the logistic function. Second, the non-additive error structure of $\varepsilon_{i t}$ is more appropriate to satisfy normality assumptions. Third, the logit formulation does not place any restrictions on the autoregressive process of the structural error term (Chavas and Segerson, 1986).

The linear logit model is well suited to satisfy theoretical restrictions. Zero degree homogeneity can be imposed as

$$
\sum_{i=c, g, o, e} \phi_{i j}=d,
$$

where $d$ is an arbitrary constant. To impose symmetry conditions, the price coefficients should be redefined as

$$
\phi_{i j}^{*}=\frac{\phi_{i j}}{S_{i t}^{*}},
$$

where $S_{i t}^{*}$ are the equilibrium (time-invariant) fuel cost shares, and

$$
\phi_{i j}^{*}=\phi_{j i}^{*} .
$$

Using the redefined parameters (4), restating homegeneity constraints (3) and imposing symmetry constraint (5) yields the following system of share equations estimated in this study:

$$
\begin{gathered}
\ln \left(\frac{S_{c}}{S_{e}}\right)_{k t}=\left(\mu_{c}-\mu_{e}\right)_{k}-\left(\phi_{c g}^{*} S_{g t}^{*}+\phi_{c o}^{*} S_{o t}^{*}+\phi_{c e}^{*}\left(S_{c t}^{*}+S_{e t}^{*}\right)\right) \ln \left(\frac{P_{c}}{P_{e}}\right)_{t} \\
+\left(\phi_{c g}^{*}-\phi_{g e}^{*}\right) S_{g t}^{*} \ln \left(\frac{P_{g}}{P_{e}}\right)_{t}+\left(\phi_{c o}^{*}-\phi_{o e}^{*}\right) S_{o t}^{*} \ln \left(\frac{P_{o}}{P_{e}}\right)_{t}+\lambda \ln \left(\frac{Q_{c}}{Q_{e}}\right)_{k, t-1} \\
+\left(\gamma_{c y}-\gamma_{e y}\right) \ln y_{k t}+\left(\gamma_{c \tau}-\gamma_{e \tau}\right) t+\left(\varepsilon_{c}-\varepsilon_{e}\right)_{k t},
\end{gathered}
$$




$$
\begin{gathered}
\ln \left(\frac{S_{g}}{S_{e}}\right)_{k t}=\left(\mu_{g}-\mu_{e}\right)_{k}-\left(\phi_{c o}^{*} S_{c t}^{*}+\phi_{g o}^{*} S_{o t}^{*}+\phi_{g e}^{*}\left(S_{g t}^{*}+S_{e t}^{*}\right)\right) \ln \left(\frac{P_{g}}{P_{e}}\right)_{t} \\
+\left(\phi_{c g}^{*}-\phi_{c e}^{*}\right) S_{c t}^{*} \ln \left(\frac{P_{c}}{P_{e}}\right)_{t}+\left(\phi_{g o}^{*}-\phi_{o e}^{*}\right) S_{o t}^{*} \ln \left(\frac{P_{o}}{P_{e}}\right)_{t}+\lambda \ln \left(\frac{Q_{g}}{Q_{e}}\right)_{k, t-1} \\
+\left(\gamma_{g y}-\gamma_{e y}\right) \ln y_{k t}+\left(\gamma_{g \tau}-\gamma_{e \tau}\right) t+\left(\varepsilon_{g}-\varepsilon_{e}\right)_{k t}, \\
\begin{array}{r}
\ln \left(\frac{S_{o}}{S_{e}}\right)_{k t}=\left(\mu_{o}-\mu_{e}\right)_{k}-\left(\phi_{c o}^{*} S_{c t}^{*}+\phi_{g o}^{*} S_{g t}^{*}+\phi_{o e}^{*}\left(S_{o t}^{*}+S_{e t}^{*}\right)\right) \ln \left(\frac{P_{o}}{P_{e}}\right)_{t} \\
+\left(\phi_{c o}^{*}-\phi_{c g}^{*}\right) S_{c t}^{*} \ln \left(\frac{P_{c}}{P_{e}}\right)_{t}+\left(\phi_{g o}^{*}-\phi_{g e}^{*}\right) S_{g t}^{*} \ln \left(\frac{P_{g}}{P_{e}}\right)_{t}+\lambda \ln \left(\frac{Q_{o}}{Q_{e}}\right)_{k, t-1} \\
+\left(\gamma_{o y}-\gamma_{e y}\right) \ln y_{k t}+\left(\gamma_{o \tau}-\gamma_{e \tau}\right) t+\left(\varepsilon_{o}-\varepsilon_{e}\right)_{k t} .
\end{array}
\end{gathered}
$$

The equation system (6) - (8) requires some clarification. First of all, it should be noted that it allows for country-specific fixed effects, represented by suffix $k$ in each equation. Hausman's (1978) specification test is employed to verify if the model can be pooled across sectors, and its estimates remain consistent. ${ }^{4}$ Second, we specify the control variables entering the vector $W$ in equation (2). These variables are the natural logarithm of industrial output, $\ln y_{k t}$, that accounts for unobserved structural changes in the economy, which affect the countries' fuel intensity, and a time trend, $t$, that measures the efficiency gains or exogenous technical change in countries' fuel consumption ${ }^{5}{ }^{6}$ Third, we need identifying ("adding-up") restrictions to obtain model estimates: $\mu_{e}=\gamma_{e y}=$ $\gamma_{e \tau}=\gamma_{e h}=d=0 .{ }^{7}$ Fourth, homegeneity and symmetry constraints defined by equations (3) and (5) are based on the economic theory and employed to reduce the degrees of freedom problem. Finally, to consistently estimate the model that satisfies global constraint (5), a two-step iterative procedure suggested by Considine (1990) and described in Jones (1995, p. 460) is employed. In the first step, the actual fuel cost shares observed in each period are used in lieu of the equilibrium cost shares to estimate the parameters and produce an initial set of predicted shares for each observation. These initial predicted shares are then inserted into the model for re-estimation of parameters, yielding a new

\footnotetext{
${ }^{4}$ In this study Hausman's (1978) test is implemented as likelihood-ratio test as explained in Qian (1999).

${ }^{5}$ As the time trend is a fairly crude proxy for technological change, one should interpret the magnitude of estimated coefficients with caution. An alternative approach not pursued here is to construct more sophisticated measure of technological change, see e.g. Baltagi and Griffin (1988).

${ }^{6}$ Other control variables include the Battese-Nerlove dummy variables (Battese, 1997), which take values of one when fuel cost share ratios are zero or very close to zero, and zero otherwise, to account for corner solutions. These control variables are not of substantial policy interest, and therefore, are not reported in the empirical specification $(6)-(8)$.

${ }^{7}$ Considine and Mount (1984, p.437) note that these constraints have no effect on any of the computed elasticities.
} 
set of predicted shares. This process continues until the parameter estimates converge. The nonlinear iterative seemingly unrelated estimation procedure is employed to estimate the model.

The parameters central to this study are the elasticities of fuel demand implied by equations (6) - (8). Complete derivation of all elasticities can be found in Jones (1995), and Considine (1989, 1990); for brevity, only final forms (evaluated at sample means) are presented. The short run own price fuel demand elasticities, $\eta_{i i}^{S R}$, are calculated as

$$
\eta_{i i}^{S R}=\left(\phi_{i i}^{*}+1\right) \bar{S}_{i}-1, i=c, g, o, e,
$$

where $\bar{S}_{i}$ are time-invariant sample means of fuel cost shares and $\phi_{i i}^{*}$ is

$$
\begin{aligned}
& \phi_{c c}^{*}=-\frac{\phi_{c g}^{*} \bar{S}_{g}+\phi_{c o}^{*} \bar{S}_{o}+\phi_{c e}^{*} \bar{S}_{e}}{\bar{S}_{c}}, \\
& \phi_{g g}^{*}=-\frac{\phi_{c g}^{*} \bar{S}_{c}+\phi_{g o}^{*} \bar{S}_{o}+\phi_{g e}^{*} \bar{S}_{e}}{\bar{S}_{g}}, \\
& \phi_{o o}^{*}=-\frac{\phi_{c o}^{*} \bar{S}_{c}+\phi_{g o}^{*} \bar{S}_{g}+\phi_{o e}^{*} \bar{S}_{e}}{\bar{S}_{o}}, \\
& \phi_{e e}^{*}=-\frac{\phi_{c e}^{*} \bar{S}_{c}+\phi_{g e}^{*} \bar{S}_{g}+\phi_{o e}^{*} \bar{S}_{o}}{\bar{S}_{e}} .
\end{aligned}
$$

The short run cross price elasticities of fuel demand, $\eta_{i j}^{S R}$, are calculated as

$$
\eta_{i j}^{S R}=\left(\phi_{i j}^{*}+1\right) \bar{S}_{j}, i, j=c, g, o, e, i \neq j .
$$

The short run partial elasticities of fuel demand (i.e., with respect to control variables), $\eta_{i w}^{S R}$, can be calculated as

$$
\eta_{i w}^{S R}=\gamma_{i m}-\sum_{j \neq i} \gamma_{j m} \bar{S}_{j}+\frac{\partial \ln C_{t}}{\partial w_{m}}, i, j=c, g, o, e ; m=\ln y, t .
$$

Following Considine (1990), the following cost function is estimated to obtain the partial elasticities ${ }^{8}$ :

$$
\begin{aligned}
\ln C_{t}= & \alpha_{k}+\sum_{i=c, g, o, e} S_{i t}^{*} \ln P_{i t}+\gamma_{y} \ln y_{k t}+\gamma_{y y}\left(\ln y_{k t}\right)^{2} \\
& +\gamma_{y \tau}\left(\ln y_{k t}\right) t+\gamma_{\tau} t+\gamma_{\tau \tau} t^{2}+\varepsilon_{k t} .
\end{aligned}
$$

Finally, the corresponding long $\operatorname{run}^{9}$ fuel demand elasticities are:

\footnotetext{
${ }^{8}$ Note that estimates for cost function are not needed to calculate homothetic price elasticities of fuel demand.

${ }^{9}$ As model specification described by equations (6) - (8) includes fixed effects, the parameter $\lambda$ captures adjustment only across time, and not across both time and countries. Estimated elasticities therefore capture fuel demand responsiveness in the medium run to long run rather than in the very long run.
} 


$$
\eta_{i j}^{L R}=\frac{\eta_{i j}^{S R}}{1-\lambda}, \forall i, j
$$

and

$$
\eta_{i w}^{L R}=\frac{\eta_{i w}^{S R}}{1-\lambda}, \forall i, w
$$

\section{Data}

The empirical analysis is based on a comprehensive unbalanced panel dataset that comprises 63 countries over the period 1978 - 2008 (for details, see Table A.1, Appendix I). We focus on the industrial consumption of four fuels - coal, natural gas, petroleum products, and electricity. Following Jones (1995), we exclude the consumption of fuels used for non-energy purposes. Specifically, among coal categories we include steam coal, and exclude coking coal. We combine the industrial consumption of natural gas and liquefied petroleum gases (LPG), as those products are close technological substitutes and have similar energy use (Steinbuks, 2012). The petroleum products category comprises consumption of light fuel oils, diesel, naphtha, and high-sulphur fuel oils. Finally, we treat electricity as homogenous energy service and do not differentiate across the sources of electricity generation. ${ }^{10}$ We obtain country fuel consumption and production data from the World Energy Statistics and Balances, published by the International Energy Agency (IEA).

As fossil fuel production is potentially endogenous to unobserved variables affecting fuel demand (e.g., indirect subsidies, government regulations, and capital market imperfections) we use tobit estimates of fuel production instrumented by countries' size of natural resource endowment normalized by its 10 year average resource consumption. ${ }^{11}$ Using natural resource endowment is a natural choice for instrumenting fuel production. By Hotelling's (1931) rule the size of natural resource stocks is a critical determinant of fossil fuel extraction decision yet it is uncorrelated with unobserved variables mentioned above. This instrumented variable thus reflects not the actual fuel production but rather the extent to which domestic fuel production is feasible (although these measures are closely correlated). For information on countries' natural resource (respectively, coal, natural gas, and oil) endowments we use the BP Statistical Review of World Energy database. ${ }^{12}$

\footnotetext{
${ }^{10}$ This is because we are only interested in the downstream competition for energy fuels, where firms take the electricity price as given. The on-site electric power generation is negligible for a vast majority of manufacturing industries, and its impact can be ignored at the chosen level of aggregation.

${ }^{11} \mathrm{We}$ do not instrument for electricity production for two reasons. First, as electricity is difficult to store and electricity imports are not always reliable, all countries in the sample produce electricity. Second, as all countries in the sample have access to renewable electricity resources of some sort (biomass, solar, wind, or hydro), instrumenting for electricity will always yield positive production.

${ }^{12}$ Detailed information on the BP Statistical Review of World Energy database can
} 
Table 2: Predicted Energy Production across Countries, 2008

\begin{tabular}{lcc}
\hline Resources & Obs. & \% of Total \\
Coal Only & 6 & 9.52 \\
Natural Gas Only & 5 & 7.94 \\
Oil Only & 1 & 1.59 \\
Coal and Natural Gas & 3 & 4.76 \\
Coal and Oil & 1 & 1.59 \\
Oil and Natural Gas & 11 & 17.46 \\
All 3 Resources & 17 & 26.98 \\
None & 19 & 30.16 \\
Total & 63 & 100.00 \\
\hline
\end{tabular}

Note: (i) Obs. = number of observations

Source: EIA International Energy Statistics

Table 2 describes the distribution of natural reserves across countries in the dataset in 2008 (for more details, see Table A.2, Appendix I). Most countries in the dataset either cannot produce any energy resources (19 countries or $30.16 \%$ of the sample $)^{13}$ or have a potential to produce all energy resources (17 countries or $26.98 \%$ of the sample). A smaller share of countries have the potential to produce oil and gas but not coal (11 countries or $17.46 \%$ of the sample). Some countries have the potential to produce solely coal (6 countries or $9.5 \%$ of the sample), or natural gas ( 5 countries or $7.94 \%$ of the sample). Finally, a small share of countries have the potential to produce coal and natural gas (3 countries or $4.76 \%$ of the sample), coal and oil, or solely oil (both 1 country or $1.59 \%$ of the sample). Most of these country groups separately account for a relatively small number of observations to yield empirically plausible estimates. To avoid this problem, we aggregate the countries in the dataset into three broad groups. First group of countries has a potential to produce any of the three energy resources. Second group of countries has a potential to produce one or two of three energy resources. Third group of countries does not have a potential to produce energy resources.

A well known problem in the econometric analysis of interfuel substitution in an international context is the limited availability of sound energy price data. While energy consumption data are readily available for almost all countries, the fuel price data exist for a relatively small number of countries (Serletis et al., 2010b). The individual fuel prices, in real terms (2005 U.S. dollars per tonne of oil equivalent), come from two sources: Energy Prices and Taxes published

be found on the following website: http://www.bp.com/en/global/corporate/about-bp/ energy-economics/statistical-review-of-world-energy-2013.html

${ }^{13}$ This category also comprises countries with very small predicted fossil fuel production (i.e., below 100 tonnes of oil equivalent per annum). 
by the IEA, and SIEE (Energy Economic Information System) database maintained by Latin American Energy Organization (OLADE). ${ }^{14}$ For natural gas and petroleum products aggregates, we define fuel prices as consumption-weighted averages of individual fuel prices. If industrial sector prices are not available, we use different proxies, such as comparable fuel prices in other sectors.

We obtain the data on country-level industrial output in real terms (expressed as the gross value added in manufacturing sector in 2005 U.S. dollars) from the United Nations Statistics Division (http://data.un.org).

Table 3 shows the descriptive statistics for energy prices, taxes, and consumption (relative to output) of fossil fuels and electricity in 2005 across countries grouped by their potential to produce fossil fuels. Countries that have a potential to produce any of the three fossil fuels have considerably lower enduse prices of coal, natural gas, petroleum products, and electricity compared to the rest of the sample. Countries that cannot produce any fossil fuels have the highest end-use prices for all energy sources. Energy prices in countries that can produce one or two fossil fuels are in between two previous groups. The end-use prices of coal, petroleum products, and electricity are about 1.3 to 1.5 times higher in countries that cannot produce any fossil fuels. The end-use prices of natural gas in these countries are about 2 times higher compared to countries that have a potential to produce any of the three fossil fuels, and about 1.3 times higher compared to countries that have a potential to produce one or two fossil fuels. The end-use prices of coal, petroleum products, and electricity are of a similar magnitude for countries that have a potential to produce one or two fossil fuels and countries that cannot produce any fossil fuels.

There is a significant heterogeneity in energy taxes across different country groups. Taxes on coal and natural gas are considerably (2 to 4 times) lower in countries with the potential to produce all three fossil fuels or at least one fossil fuel, compared to countries that cannot produce fossil fuels. This finding is consistent with the historical evidence of subsidizing energy production in coal and natural gas rich economies. Taxes on petroleum products across country groups exhibit a similar pattern but the difference magnitude (1.2 to 1.65 times) is more subtle. Countries with the potential to produce all three fossil fuels also have the lowest tax on electricity, which is 2 times smaller compared to countries that have a potential to produce one or two fossil fuels, and 1.4 times smaller compared to countries that cannot produce any fossil fuels.

Table 3 also shows that countries with the potential to produce all three fossil fuels or at least one fossil fuel are more intensive in use of coal, natural gas, and electricity compared to countries that cannot produce fossil fuels. Countries that have a potential to produce any of the three fossil fuels are 4 times more intensive in their use of coal and natural gas, and 1.5 times more intensive in use of electricity compared to countries that cannot produce any fossil fuels. Similarly, countries that have a potential to produce one or two of three fossil fuels are 2 times more intensive in their use of coal and natural gas, and 1.2

\footnotetext{
${ }^{14}$ Detailed information on SIEE database can be found on the following website: http: //www.olade.org.ec/en/product/SIEE
} 


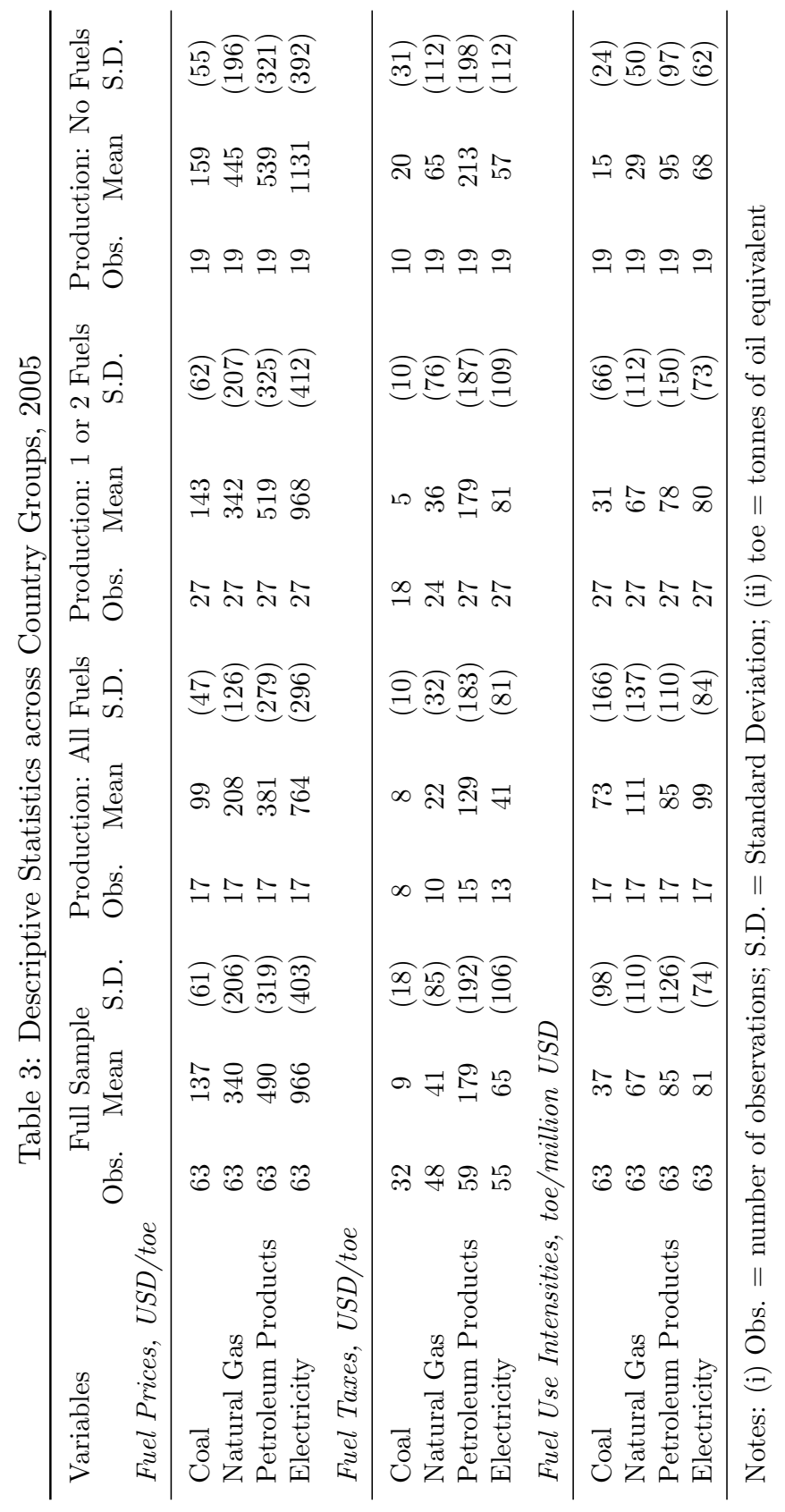


times more intensive in use of electricity compared to countries that cannot produce any fossil fuels. However, there are no substantial differences in the intensive use of petroleum products across country groups.

\section{Results}

Table 4 presents the parameter estimates and summary statistics for dynamic linear logit model (equations 6-8) applied to fuel consumption across the entire dataset, and separately to the country groups defined in the previous section. All model specifications have a reasonably good fit, characterized by high pseudoR squares. The results from Hausman's (1978) specification test indicate that the hypothesis that a pooled model's estimates are consistent is rejected at a 1 percent level of significance for all model specifications. Estimates of structural parameters $\phi_{i j}^{*}$ vary across country groups, indicating heterogeneity in estimated elasticities.

Econometric estimates of the adjustment parameter $\lambda$ reveal that fuel demand is responsive in the short run, with about two-thirds of the long run response taking place in the same year as the price change. The size of the estimated adjustment parameter is the highest for countries that have a potential to produce any of the three fossil fuels. For these countries less than a half of the long run response takes place in the same year as the fuels' price change. The size of the estimated adjustment parameter is considerably smaller for countries that have a potential to produce one or two fossil fuels. For these countries about 70 percent of the long run response takes place in the same year as the fuels' price change. The size of the estimated adjustment parameter is the smallest for countries that have no potential to produce any of the three fossil fuels. For these countries about 90 percent of the long run response takes place in the same year as the fuels' price change. These results indicate that more fossil fuel-intensive industries of energy producers have higher capital adjustment costs, and are consistent with the carbon lock-in hypothesis.

As regards other explanatory variables, the coefficients of the logarithm of real gross value added are negative (and, in most cases, statistically significant) across all country groups, except for countries that have no potential to produce any of the three fossil fuels. These results imply that, as output increases, the shares of coal, natural gas, and petroleum products in the industrial fuel mix decline, and the share of electricity increases. For countries that have no potential to produce any of the three fossil fuels, the coefficients of the logarithm of real gross value added are positive (and statistically significant for natural gas-to-electricity and petroleum products-to-electricity ratios). These results imply that, as output increases, the share of electricity in the industrial fuel mix decreases, and the shares of natural gas and petroleum products increase.

Finally, the estimated coefficients for the time trend are negative and statistically significant for the petroleum products-electricity ratio across all groups of countries. The estimated coefficients for natural gas-electricity ratio are positive and statistically significant across all groups of countries, except for the coun- 


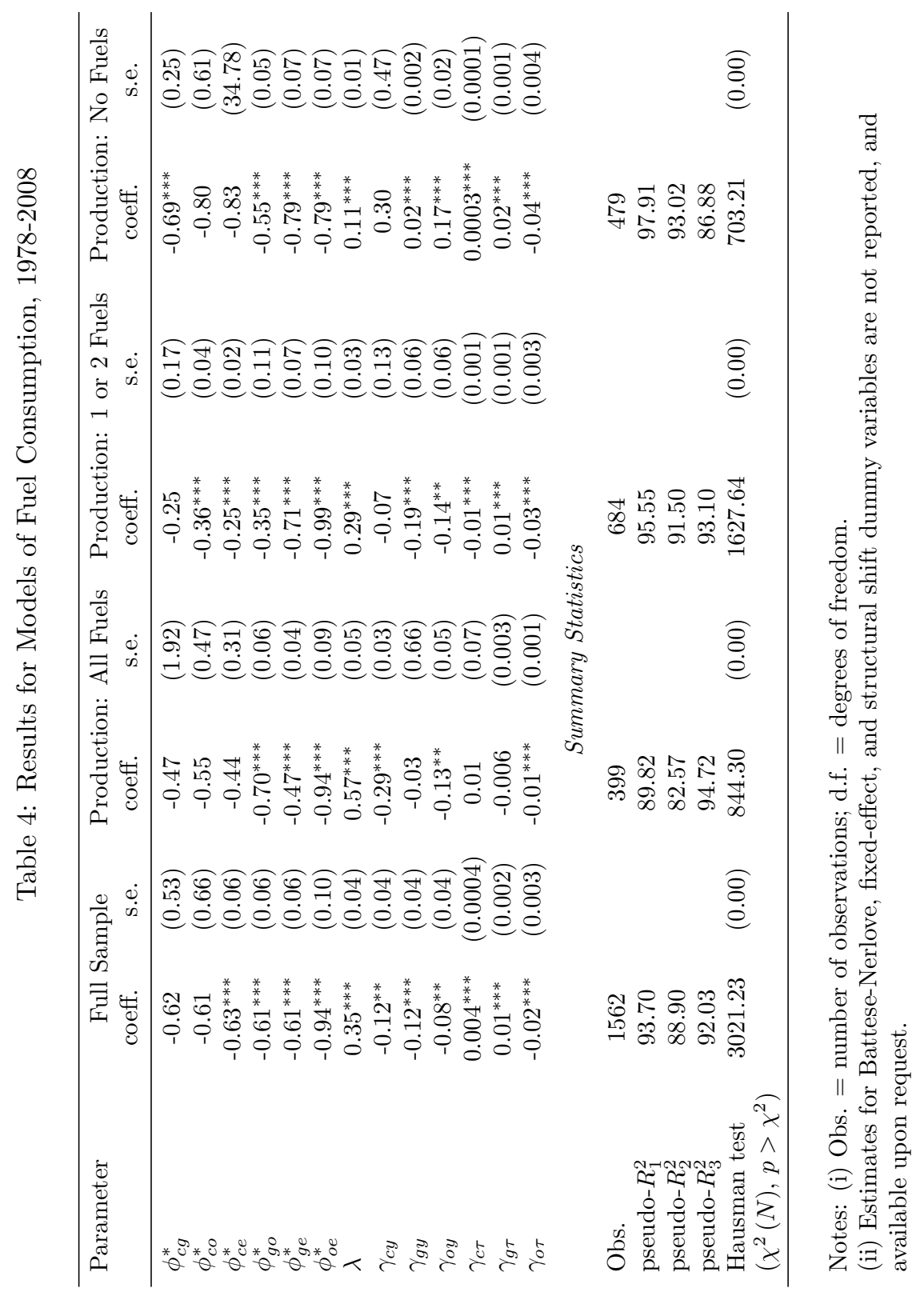


tries that have a potential to produce any of the three fossil fuels. The estimated coefficients for coal-electricity ratio are positive and statistically significant for the full sample, and for countries that have no potential to produce fossil fuels. The estimated coefficients for coal-electricity ratio are positive and not statistically significant for countries that have a potential to produce any of the three fossil fuels. The estimated coefficients for coal-electricity ratio are negative and statistically significant for countries that have a potential to produce one or two fossil fuels. These results indicate that the direction of the technological change in fuel choice is from petroleum products to electricity and natural gas.

\subsection{Elasticities}

Tables 5 and 6 show the estimated short run and long run elasticities of fuel demand evaluated at the sample means for fuel consumption across the entire dataset, and separately to country groups based on their potential to produce energy fuels. All of the estimated own price elasticities are statistically significant at the $1 \%$ level. Estimated elasticities have expected signs and are broadly comparable to the results from recent studies on international interfuel substitution.

\subsubsection{Own Price Elasticities}

The top section of Tables 5 and 6 shows the estimated short run and long run own price elasticities of demand for coal, natural gas, petroleum products, and electricity. The demand for all fuels is inelastic in both the short run and the long run. Petroleum products and electricity are the most inelastic energy services, with the estimated short run own price elasticities of -0.1 and -0.08 , using the full dataset. Demand for other fossil fuels is more elastic. Estimated short run own price elasticities using full dataset are -0.34 for natural gas and -0.36 for coal. In the long run demand for petroleum products and electricity is still very unresponsive to fuel prices, with estimated own price elasticities of -0.15 and -0.12 , using the full dataset. Demand for coal and natural gas becomes more responsive to fuel prices, with estimated long run own price elasticities of -0.56 and -0.52 .

Estimated own price elasticities of demand for coal vary significantly across different country groups. In the short run, own price elasticities of coal, natural gas, and electricity demand are all smaller for countries that have no potential to produce fossil fuels. Own price elasticities of coal demand in those countries are about 2.5 times smaller compared to countries that have a potential to produce all fossil fuels, and about 3.5 times smaller compared to countries that

have a potential to produce one or two fossil fuels. Own price elasticities of natural gas demand in those countries are about 1.5 times smaller compared to countries that have a potential to produce all fossil fuels. Own price elasticities of electricity demand in those countries are about 1.3 times smaller compared to countries that have a potential to produce all fossil fuels, but 1.5 times larger compared to countries that have a potential to produce one or two fossil fuels. 


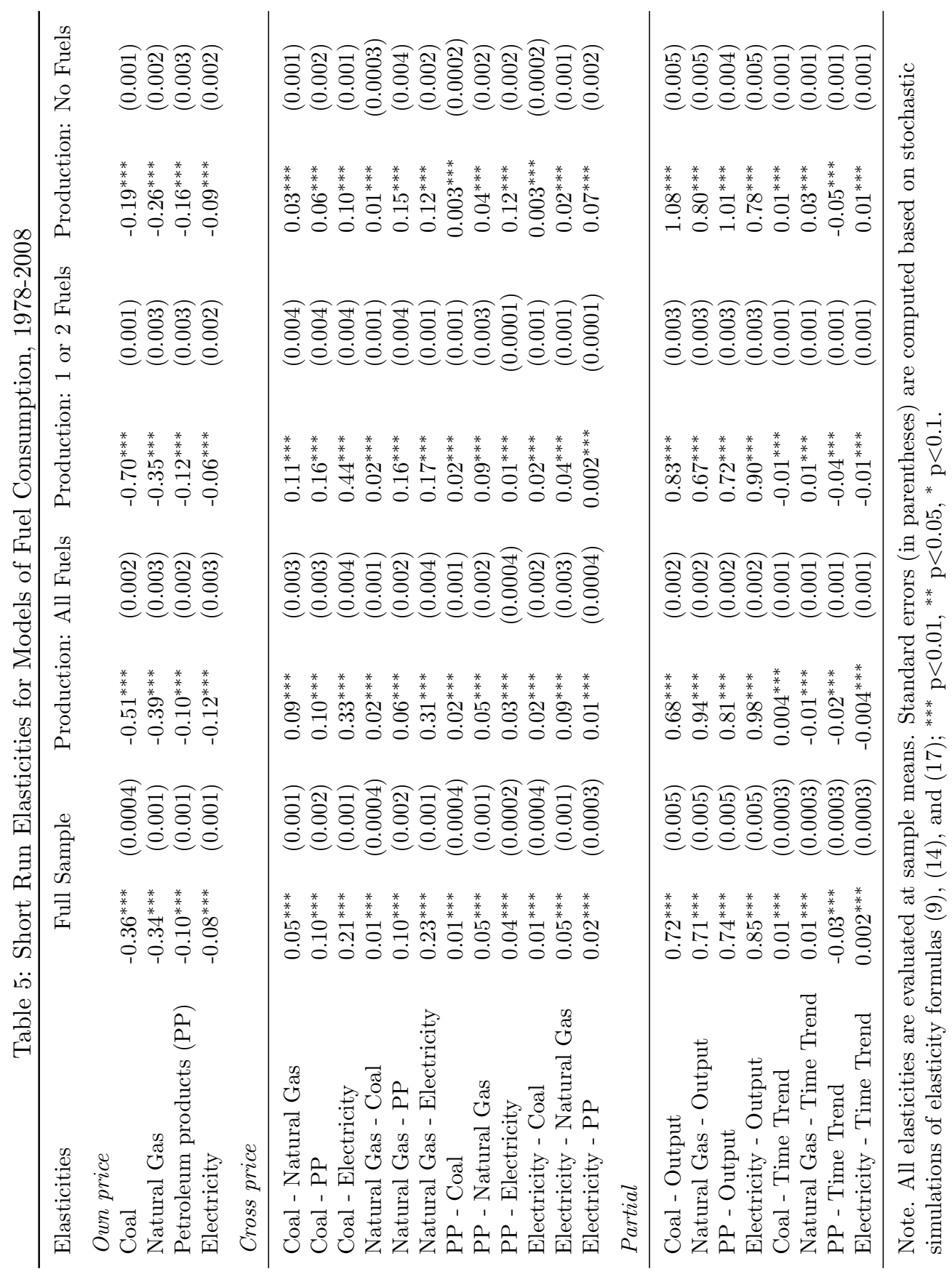




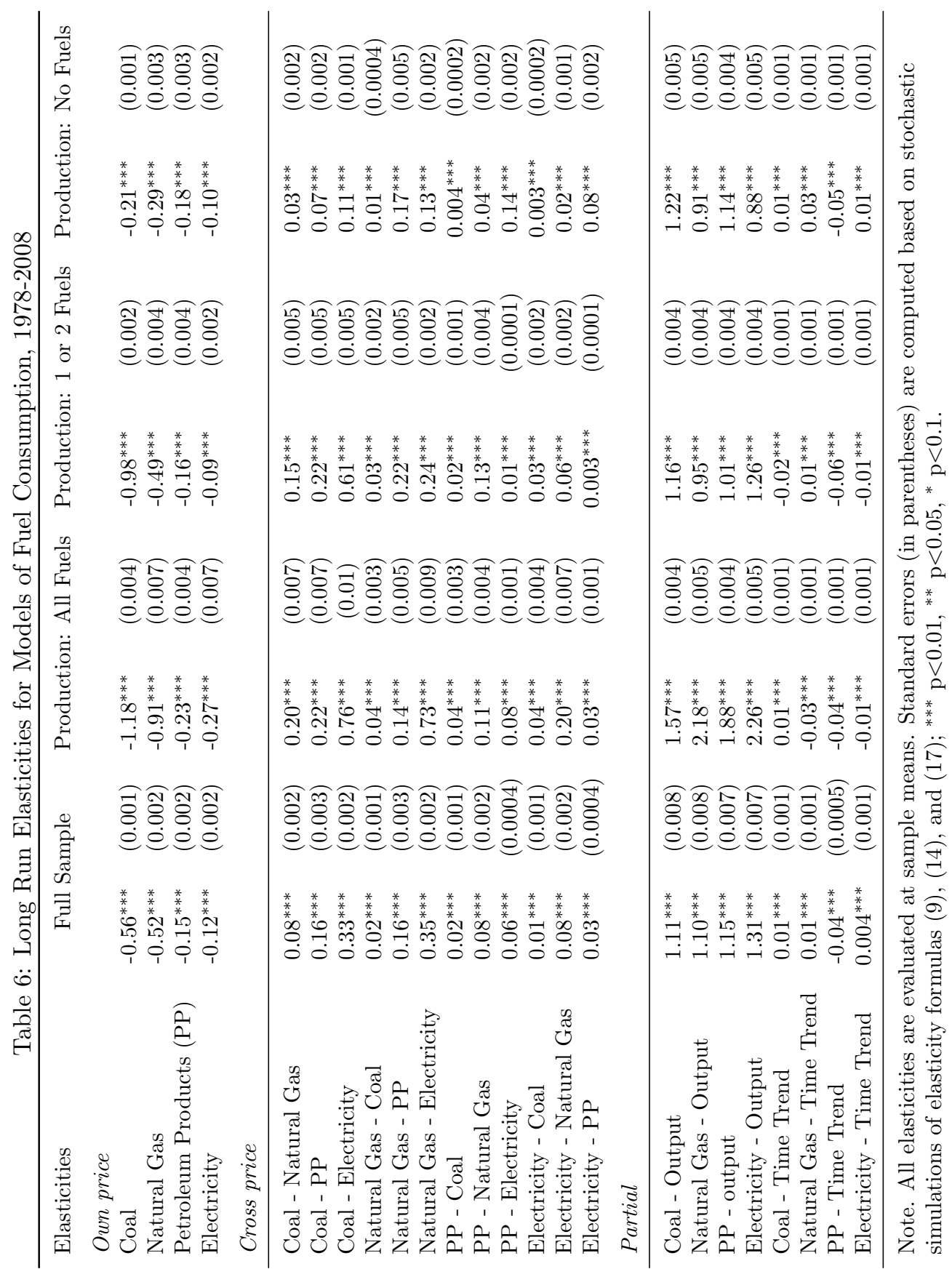


However, the short run own price elasticities of petroleum products demand are 1.3 to 1.6 times larger for countries that have no potential to produce fossil fuels relative to energy-producing countries.

In the long run, own price elasticities of demand for all energy sources are larger for countries that have potential to produce any of fossil fuels. Own price elasticities of coal demand in those countries are about 6 times larger compared to countries that have no potential to produce any of energy fuels, and about 1.2 times larger compared to countries that have a potential to produce one or two fossil fuels. Own price elasticities of natural gas demand in those countries are about 3 times larger compared to countries that have no potential to produce all fossil fuels, and about 1.8 times larger compared to countries that have a potential to produce one or two fossil fuels. Own price elasticities of petroleum products demand in those countries are about 1.3 to 1.4 times larger compared to countries that have a potential to produce one or two of fossil fuels or cannot produce any fossil fuels. Own price elasticities of electricity demand in those countries are about 3 times larger compared to countries that have a potential to produce one or two of fossil fuels or cannot produce any energy fuels.

\subsubsection{Cross Price Elasticities}

The middle section of Tables 5 and 6 shows the estimated short run and long run cross price elasticities of fuel demand with respect coal, natural gas, petroleum, and electricity prices. Estimated cross price elasticities are all positive in both short and the long run, indicating that all four fuels are substitutes. Those elasticities are, however, small in their absolute magnitude (less or equal to 0.23 in the short run, using full dataset), indicating limited possibilities for interfuel substitution. The largest scope for interfuel substitution is for coal and natural gas with respect to electricity prices $(0.21$ and 0.23 in the short run using full dataset) and petroleum products prices (0.1 in the short run using full dataset). Both petroleum products and electricity appear to be very poor substitutes to other fuels with estimated short run elasticities less than 0.05 using full dataset.

As regards variation across country groups based on natural resources, estimates of both short and long run cross price elasticities do vary significantly across different country groups. Specifically, estimated cross price elasticities of coal with respect to other fuels' prices, and cross price elasticities of other fuels with respect to coal's prices are all considerably higher for countries with the potential to produce all fossil fuels or at least one fossil fuel. The largest estimated short run cross price elasticity is of coal with respect to electricity prices for countries with the potential to produce at least one fossil fuel (0.44), which is more than 4 times higher than for countries with no potential to produce any fossil fuels. Similarly, estimated short run cross price elasticities of natural gas with respect to electricity prices, and of electricity and petroleum products with respect to natural gas prices are higher for countries with the potential to produce all fossil fuels or at least one fossil fuel. These differences become even more pronounced in the long run. This is because (as shown in the section above) the countries with the potential to produce fossil fuels account 
for smaller share of the long run response in the year of the fuels' price change. On the contrary, estimated cross price elasticities of petroleum products with respect to electricity prices, and of electricity with respect to petroleum prices are higher for countries with the potential to produce all fossil fuels or at least one fossil fuel. Finally, estimated short run cross price elasticity of natural gas with respect to petroleum prices, is smaller for countries with the potential to produce all fossil fuels than in other countries. This difference becomes smaller in the long run.

\subsubsection{Partial Elasticities}

The bottom section of Tables 5 and 6 shows the estimated partial elasticities of fuel demand with respect to changes in manufacturing output and time trend. Estimated average elasticities of fuel demand with respect to output are all positive and less than one, indicating that "as output increases there will be substitution away from energy" (Pindyck 1979, p. 176). In the long run, output elasticities of fuel demand are all above one, which implies that an increase in output results in more than proportional increase in energy consumption. Estimated short run elasticities of coal and petroleum products demand with respect to output are largest for countries with no potential to produce fossil fuels. Estimated short run elasticities of natural gas and electricity demand with respect to output are largest for countries with the potential to produce all fossil fuels. Estimated long run elasticities of all four fuels with respect to output are largest for countries with the potential to produce all fossil fuels.

Estimated average elasticities of fuel demand with respect to time trend are positive for coal, natural gas and electricity, and negative for petroleum products. This result implies that the technological change results in greater consumption of coal, natural gas and electricity, and smaller consumption of petroleum products. However, the estimated elasticities of fuel demand with respect to time trend are negative for natural gas, petroleum products, and electricity for countries with the potential to produce all fossil fuels. Similarly, the estimated elasticities of fuel demand with respect to time trend are negative for coal, petroleum products, and electricity for countries with the potential to produce at least one fossil fuel. These results indicate that technological change results in smaller fuel consumption in energy producing economies.

\subsubsection{Comparisons with other Elasticity Estimates}

As discussed above there are just handful of studies on international interfuel substitution, most of which are quite outdated in terms of both data and econometric methodology, and have limited country coverage. Despite these limitations it may be still helpful to compare our results with most relevant studies (see Table 1 above) to better understand how the econometric methodology and data series may influence the results.

Our short run own price elasticities (see Table 5) are smaller than in Hall (1986), and of similar magnitude to Agostini et al. (1992) and Serletis et al. 
(2010b). Our long run own price elasticities (see Table 6) are smaller than in Pindyck (1979), and of similar magnitude to Jones (1996) (with notable exception of oil and petroleum products) and Renou-Maissant (1999). The differences between our calculations and Pindyck (1979) and Hall (1986) studies can be explained by numerous structural changes in factors affecting industrial fuel demand since 1980 s, as well as, to some extent, by methodological issues. ${ }^{15}$ The differences between our study and that of Jones (1996) for oil and petroleum products are more difficult to reconcile, as Jones (1996) employs similar econometric methodology and more recent data than Pindyck (1979) and Hall (1986). There are two potential explanations for why the own price elasticity for oil and petroleum products of Jones (1996) is larger in magnitude. First, Jones (1996) estimates are pooled across his sample, whereas we do control for country specific fixed effects. Elasticities of Jones (1996) (and also of Pindyck 1979) thus capture longer adjustment span and are expected to be larger in magnitude. Second, smaller magnitude of the elasticity for oil and petroleum products in our study may be because of larger number of countries with less integrated oil trade than G-7 economies studied by Jones (1996).

The results for cross price elasticities are more difficult to reconcile because of high variation in their estimates across studies. Our results appear closest in magnitude to estimates of Agostini et al. (1992) and Renou-Maissant (1999), and overlap with Serletis et al. (2010b) for most fuel pairs. As all these studies employ different econometric methods, our findings imply that structural changes in fuel demand and pooling across countries are more significant drivers explaining variation in cross price elasticity estimates.

\section{Conclusions}

This study extends the literature on interfuel substitution, focusing specifically on differences across countries with different potential for fossil fuel production. We estimate an econometric model of interfuel substitution using a large unbalanced panel dataset of 63 countries, and calculate elasticities of energy demand for fossil fuel producing and non-producing economies.

We find that compared to other economies, countries with the potential to produce coal, natural gas, or oil have higher elasticities of fuel substitution in both short and long term. Furthermore, in many cases short run elasticities of fuel substitution for fossil fuel producing countries are higher than long run elasticities for countries with no potential to produce fossil fuels. The difference in substitutability of fuels in industrial energy demand between fossil fuel producing and non-producing countries increases in the long term. This is because countries with a potential to produce fossil fuels have a considerably longer adjustment of their fuel-using capital stocks. For these, more energy-intensive,

\footnotetext{
${ }^{15}$ Jones (1995) and Urga and Walters (2003) demonstrate that translog model estimates are frequently inconsistent with restrictions imposed by the economic theory, and yield implausible results, such as predicted negative cost shares, positive own price elasticities, and short run elasticities larger than long run elasticities.
} 
countries, the share of same year response to fuels' price change was less than fifty percent as opposed to ninety percent in countries with no potential to produce any fossil fuels. Thus fossil fuel producing countries have considerably higher difference between short and long run elasticities of fuel substitution.

These results have significant policy implications in light of recent efforts by the international community to reduce carbon emissions and fossil fuel subsidies. A carbon tax would deliver a greater decline in carbon-intensive fuel consumption and result in a smaller decline in industrial output in fossil fuel producing economies due to their greater ease in switching to more carbon efficient fuels. Similarly, a reduction in oil subsidies would lead to a greater decline in industrial consumption of oil and petroleum products and a smaller decline in industrial output in fossil fuel producing countries as they can more easily adopt other fuels in their industrial energy demand. Greater potential for industrial interfuel substitution in more energy-intensive fossil fuel producing economies thus implies a lower economic cost for policies aimed at climate abatement and more efficient utilization of energy resources.

\section{Acknowledgments}

The authors thank Robert McDougall, Michael Toman, the anonymous reviewer, and the participants of 4th International Workshop on Empirical Methods in Energy Economics for helpful comments and suggestions. The views expressed in this paper are those of the authors and do not necessarily reflect the opinions of the World Bank or its member countries.

\section{References}

Agostini, P., Botteon, M. and Carraro, C.: 1992, A Carbon Tax to Reduce CO2 Emissions in Europe, Energy Economics 14(4), 279-290.

Armington, P.: 1969, A Theory of Demand for Products Distinguished by Place of Production, IMF Staff papers 17, 159-176.

Balistreri, E., Al-Qahtani, A. and Dahl, C.: 2010, Oil and Petroleum Product Armington Elasticities: A New-Geography-of-Trade Approach to Estimation, The Energy Journal 31(3).

Baltagi, B. and Griffin, J.: 1988, A General Index of Technical Change, The Journal of Political Economy 96(1), 20-41.

Battese, G.: 1997, A Note on the Estimation of Cobb-Douglas Production Functions When Some Explanatory Variables Have Zero Values, Journal of Agricultural Economics 48(1-3), 250-252.

Berndt, E., Morrison, C. and Watkins, G.: 1981, Dynamic Models of Energy Demand: An Assessment and Comparison, in Measuring and Modeling Natural Resource Substitution (ed. E. Berndt and B. Field), MIT Press. 
Bosetti, V., Carraro, C., Galeotti, M., Massetti, E. and Tavoni, M.: 2006, A World Induced Technical Change Hybrid Model, The Energy Journal 27(S2), 13-38.

Brännlund, R. and Lundgren, T.: 2004, A Dynamic Analysis of Interfuel Substitution for Swedish Heating Plants, Energy Economics 26(6), 961-976.

Burniaux, J.-M. and Château, J.: 2008, An Overview of the OECD ENVLinkages Model, OECD Economics Department Working Paper 653, OECD Publishing.

Burniaux, J.-M. and Château, J.: 2011, Mitigation Potential of Removing Fossil Fuel Subsidies: A General Equilibrium Assessment, OECD Economics Department Working Paper 853, OECD Publishing.

Burniaux, J. and Truong, T.: 2002, GTAP-E: An Energy-Environmental Version of the GTAP Model, GTAP Technical Paper 16, Center for Global Trade Analysis, Purdue University.

Chavas, J. and Segerson, K.: 1986, Singularity and Autoregressive Disturbances in Linear Logit Models, Journal of Business 83 Economic Statistics 4(2), 161169.

Considine, T.: 1989, Separability, Functional Form and Regulatory Policy in Models of Interfuel Substitution, Energy Economics 11(2), 82-94.

Considine, T.: 1990, Symmetry constraints and variable returns to scale in logit models, Journal of Business \& Economic Statistics 8(3), 347-353.

Considine, T. and Mount, T.: 1984, The Use of Linear Logit Models for Dynamic Input Demand Systems, The Review of Economics and Statistics 66(3), 434443.

Hall, V. B.: 1986, Major OECD Country Industrial Sector Interfuel Substitution Estimates, 1960-1979, Energy Economics 8(2), 74-89.

Hausman, J.: 1978, Specification Tests in Econometrics, Econometrica 46(6), 1251-1272.

Hotelling, H.: 1931, The Economics of Exhaustible Resources, The Journal of Political Economy 39(2), 137-175.

IEA, OPEC, OECD and World Bank: 2010, Analysis of the Scope of Energy Subsidies and Suggestions for the G-20 Initiative, Joint report, prepared for submission to the G-20 meeting of the Finance Ministers and Central Bank Governors, Busan (Korea), 5 June and 26 May.

IPCC: 2007, Climate Change 2007: Synthesis Report, Contribution of working groups $i$, ii and iii to the fourth assessment report of the intergovernmental panel on climate change, Intergovernmental Panel on Climate Change: Geneva, Switzerland. 
Jacoby, H. D. and Wing, I. S.: 1999, Adjustment Time, Capital Malleability and Policy Cost, Energy Journal 20(S), 73-92.

Jones, C.: 1995, A Dynamic Analysis of Interfuel Substitution in US Industrial Energy Demand, Journal of Business \& Economic Statistics 13(4), 459-465.

Jones, C.: 1996, A Pooled Dynamic Analysis of Interfuel Substitution in Industrial Energy Demand by the G-7 Countries, Applied Economics 28(7), 815821.

Kim, S. H., Edmonds, J., Lurz, J., Smith, S. J. and Wise, M.: 2006, The ObjECTS Framework for Integrated Assessment: Hybrid Modeling of Transportation, The Energy Journal 27(S2), 63-92.

Kosmo, M.: 1987, Money to Burn. The High Costs of Energy Subsidies, Working paper, World Resources Institute, Washington, DC.

Manne, A. and Richels, R.: 2005, MERGE: An Integrated Assessment Model for Global Climate Change, Energy and Environment pp. 175-189.

McDougall, R. and Golub, A.: 2007, GTAP-E: A Revised EnergyEnvironmental Version of the GTAP Model, GTAP Research Memorandum 16, Center for Global Trade Analysis, Purdue University.

Paltsev, S., Reilly, J. M., Jacoby, H. D., Eckaus, R. S., McFarland, J. R., Sarofim, M. C., Asadoorian, M. O. and Babiker, M. H.: 2005, The MIT Emissions Prediction and Policy Analysis (EPPA) Model: Version 4, Technical report, MIT Joint Program on the Science and Policy of Global Change.

Pindyck, R.: 1979, Interfuel Substitution and the Industrial Demand for Energy: An International Comparison, The Review of Economics and Statistics 61, 169-179.

Pindyck, R. and Rotemberg, J.: 1983, Dynamic Factor Demands and the Effects of Energy Price Shocks, American Economic Review 73, 1066-1079.

Popp, D.: 2001, The Effect of New Technology on Energy Consumption, Resource and Energy Economics 23(3), 215-239.

Qian, H.: 1999, Equivalence of LR Test and Hausman Test, Econometric Theory 15(1), 157-160.

Renou-Maissant, P.: 1999, Interfuel Competition in the Industrial Sector of Seven OECD Countries, Energy Policy 27(2), 99-110.

Serletis, A. and Shahmoradi, A.: 2008, Semi-Nonparametric Estimates of Interfuel Substitution in US Energy Demand, Energy Economics 30(5), 2123-2133.

Serletis, A., Timilsina, G. and Vasetsky, O.: 2010a, Interfuel Substitution in the United States, Energy Economics 32(3), 737-745. 
Serletis, A., Timilsina, G. and Vasetsky, O.: 2010b, International Evidence on Sectoral Interfuel Substitution, The Energy Journal 31(4), 1-29.

Serletis, A., Timilsina, G. and Vasetsky, O.: 2011, International Evidence on Aggregate Short-run and Long-run Interfuel Substitution, Energy Economics 33(2), 209-216.

Steinbuks, J.: 2012, Interfuel Substitution and Energy Use in the UK Manufacturing Sector, The Energy Journal 33(1), 1-30.

Steinbuks, J. and Narayanan, B.: 2013, Fossil Fuel Producing Economies Have Greater Potential for Interfuel Substitution, GTAP Working Paper 73, Center for Global Trade Analysis, Purdue University.

Steinbuks, J. and Neuhoff, K.: 2014, Assessing Energy Price Induced Improvements in Efficiency of Capital in OECD Manufacturing Industries, Journal of Environmental Economics and Management 68(2), 340-356.

Stern, D.: 2012, Interfuel Substitution: A Meta-Analysis, Journal of Economic Surveys 26(2), 307-331.

Sue Wing, I.: 2008, Explaining the Declining Energy Intensity of the US Economy, Resource and Energy Economics 30(1), 21-49.

Unruh, G.: 2000, Understanding Carbon Lock-in, Energy Policy 28(12), 817830 .

Urga, G. and Walters, C.: 2003, Dynamic Translog and Linear Logit Models: a Factor Demand Analysis of Interfuel Substitution in US Industrial Energy Demand, Energy Economics 25(1), 1-21.

Welsch, H.: 2008, Armington Elasticities for Energy Policy Modeling: Evidence from Four European countries, Energy Economics 30(5), 2252-2264. 


\section{Appendix I}

Table A.1: Data Availability across Countries and Time

\begin{tabular}{lcclcc}
\hline Country & Obs. & Period & Country & Obs. & Period \\
\hline Argentina & 20 & $1988-2008$ & Japan & 31 & $1978-2008$ \\
Australia & 27 & $1978-2004$ & Kazakhstan & 14 & $1995-2008$ \\
Austria & 31 & $1978-2008$ & Korea & 31 & $1978-2008$ \\
Belgium & 31 & $1978-2008$ & Luxembourg & 31 & $1978-2008$ \\
Bolivia & 20 & $1988-2008$ & Mexico & 31 & $1978-2008$ \\
Brazil & 21 & $1988-2008$ & Netherlands & 31 & $1978-2008$ \\
Canada & 31 & $1978-2008$ & New Zealand & 31 & $1978-2008$ \\
Chile & 20 & $1988-2008$ & Nicaragua & 20 & $1988-2008$ \\
China & 19 & $1990-2008$ & Norway & 31 & $1978-2008$ \\
Colombia & 20 & $1988-2008$ & Panama & 20 & $1988-2008$ \\
Costa Rica & 20 & $1988-2008$ & Paraguay & 20 & $1988-2008$ \\
Croatia & 9 & $2000-2008$ & Peru & 20 & $1988-2008$ \\
Cuba & 19 & $1988-2006$ & Poland & 30 & $1979-2008$ \\
Cyprus & 31 & $1978-2008$ & Portugal & 31 & $1978-2008$ \\
Czech Republic & 19 & $1990-2008$ & Romania & 12 & $1995-2008$ \\
Denmark & 31 & $1978-2008$ & Russian Federation & 11 & $1993-2008$ \\
Dominican Republic & 19 & $1988-2006$ & Singapore & 7 & $2002-2008$ \\
Ecuador & 20 & $1988-2008$ & Slovak Republic & 19 & $1990-2008$ \\
Finland & 31 & $1978-2008$ & Slovenia & 20 & $1988-2008$ \\
France & 31 & $1978-2008$ & South Africa & 31 & $1978-2008$ \\
Germany & 31 & $1978-2008$ & Spain & 31 & $1978-2008$ \\
Greece & 31 & $1978-2008$ & Sweden & 31 & $1978-2008$ \\
Guatemala & 19 & $1988-2006$ & Switzerland & 31 & $1978-2008$ \\
Haiti & 20 & $1988-2008$ & Taiwan & 28 & $1981-2008$ \\
Honduras & 20 & $1988-2008$ & Thailand & 31 & $1978-2008$ \\
Hungary & 29 & $1980-2008$ & Trinidad and Tobago & 20 & $1988-2008$ \\
India & 31 & $1978-2008$ & Turkey & 31 & $1978-2008$ \\
Indonesia & 31 & $1978-2008$ & United Kingdom & 31 & $1978-2008$ \\
Ireland & 31 & $1978-2008$ & United States & 31 & $1978-2008$ \\
Israel & 15 & $1994-2008$ & Uruguay & 20 & $1988-2008$ \\
Italy & 31 & $1978-2008$ & Venezuela & 27 & $1981-2008$ \\
Jamaica & 19 & $1988-2006$ & & & \\
\hline & & & & &
\end{tabular}


Table A.2: Predicted Energy Production across Countries in 2008

\begin{tabular}{|c|c|c|c|c|c|c|c|}
\hline Country & Coal & Gas & Oil & Country & Coal & Gas & Oil \\
\hline Argentina & No & Yes & Yes & Japan & Yes & No & No \\
\hline Australia & Yes & Yes & Yes & Kazakhstan & Yes & Yes & Yes \\
\hline Austria & No & Yes & No & Korea & Yes & No & No \\
\hline Belgium & No & No & No & Luxembourg & No & No & No \\
\hline Bolivia & No & Yes & Yes & Mexico & Yes & Yes & Yes \\
\hline Brazil & Yes & Yes & Yes & Netherlands & No & Yes & Yes \\
\hline Canada & Yes & Yes & Yes & New Zealand & Yes & Yes & Yes \\
\hline Chile & No & Yes & No & Nicaragua & No & No & No \\
\hline China & Yes & Yes & Yes & Norway & No & Yes & Yes \\
\hline Colombia & Yes & Yes & Yes & Panama & No & No & No \\
\hline Costa Rica & No & No & No & Paraguay & No & No & No \\
\hline Croatia & No & Yes & Yes & Peru & No & Yes & Yes \\
\hline Cuba & No & Yes & Yes & Poland & Yes & Yes & No \\
\hline Cyprus & No & No & No & Portugal & No & No & No \\
\hline Czech Republic & Yes & No & No & Romania & Yes & Yes & Yes \\
\hline Denmark & No & Yes & Yes & Russian Federation & Yes & Yes & Yes \\
\hline Dominican Republic & No & No & No & Singapore & No & No & No \\
\hline Ecuador & No & Yes & Yes & Slovak Republic & No & No & No \\
\hline Finland & No & No & No & Slovenia & No & No & No \\
\hline France & Yes & No & No & South Africa & Yes & Yes & No \\
\hline Germany & Yes & Yes & Yes & Spain & Yes & No & No \\
\hline Greece & Yes & No & No & Sweden & No & No & No \\
\hline Guatemala & No & No & Yes & Switzerland & No & No & No \\
\hline Haiti & No & No & No & Taiwan & No & Yes & No \\
\hline Honduras & No & No & No & Thailand & Yes & Yes & Yes \\
\hline Hungary & Yes & Yes & No & Trinidad and Tobago & No & Yes & Yes \\
\hline India & Yes & Yes & Yes & Turkey & Yes & No & Yes \\
\hline Indonesia & Yes & Yes & Yes & United Kingdom & Yes & Yes & Yes \\
\hline Ireland & No & Yes & No & United States & Yes & Yes & Yes \\
\hline Israel & No & Yes & No & Uruguay & No & No & No \\
\hline Italy & No & Yes & Yes & Venezuela & Yes & Yes & Yes \\
\hline Jamaica & No & No & No & & & & \\
\hline
\end{tabular}

